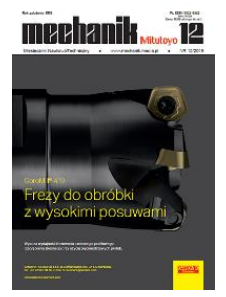

How to cite this article:

Author: Andrzej Werner

Title of article: „Evaluation of the degree of fitting of a curvilinear hole and stub machined on a CNC milling center”

Mechanik, No. 12 (2019)

DOI: https://doi.org/10.17814/mechanik.2019.12.108

\title{
Evaluation of the degree of fitting of a curvilinear hole and stub machined on a CNC milling center
}

\section{ANDRZEJ WERNER *}

Dr inż. Andrzej Werner, a.werner@pb.edu.pl, https://orcid.org/0000-0002-3768-5395 - Katedra Inżynierii Materiałowej i Produkcji, Wydział Mechaniczny, Politechnika Białostocka, Białystok, Polska

The method of evaluating the accuracy of fitting a curvilinear hole-stub pair is presented. The next stages of the process were presented, including: machining of elements, coordinate measurements of machined parts, analysis of measurement results. A method to improve the degree of fitting of the holestub pair is proposed.

KEYWORDS: curvilinear profile, hole, stub, milling, coordinate measurements

\section{Introduction}

In the production of tooling and tools, precise manufacture of products containing cooperating curvilinear geometric elements is often used [1]. Proper adjustment of the hole-stub pair significantly affects the operation of mechanisms such as blanking dies and injection mold dies.

In the case of curvilinear profiles, the assessment of manufacturing accuracy and clearances is only possible using coordinate measuring technique. Control measurements are carried out on coordinate measuring machines [2, 3] or (which is becoming more and more popular) on CNC machines [4, 5]. The disadvantage of measuring on coordinate measuring machines is the need to remove the workpiece from the machine. This forces the coordinate system to be reproduced on the measuring machine. To minimize this source of error, one must properly use the procedures offered by CMM software.

Measurements carried out on a CNC machine tool immediately after machining the workpiece do not require a change in the position of the measured object [6]. Therefore, they are not burdened with errors related to the redefinition of the workpiece coordinate system. However, they require additional equipment of the machine tool with precise measuring probes and the installation of additional measuring cycles in the machine tool controller.

In the case of curvilinear object measurements, the advantage of coordinate measuring machines over CNC machines is primarily greater precision and much more options. The results of coordinate measurements are used to assess the degree of fit of the holes and their associated stubs. If necessary, based on them, one can carry out a procedure to increase the accuracy of manufacturing cooperating elements.

The procedure proposed in the paper for assessing the degree of hole-curvilinear stub pair fitting is based on measurements made on a coordinate measuring machine. Based on the results of measurements, additional actions were taken to increase the accuracy of manufacturing of cooperating elements and to achieve the assumed gap between the elements.

\section{Assessment of the fitting degree of the hole and curvilinear stub}

Method of assessing the accuracy of the hole and curvilinear stub fitting proposed in the paper is implemented in the following stages:

- construction of the nominal geometric model of the curvilinear profile,

- preparation of machining programs for manufactured objects and their processing on a CNC milling machine,

- coordinate measurements of the hole and stub, determination of observed deviations and their components,

- determination of differences in observed deviations of hole and stub at measuring points, 
- assessment of the degree of fitting based on the distribution of determined differences of deviations and their minimum and maximum values.

Nominal profile of the hole profile and curvilinear stub is described by the NURBS curve (fig. 1). The curve was built on a control polygon consisting of 11 vertices. The degree of B-spline base functions $n=3$.

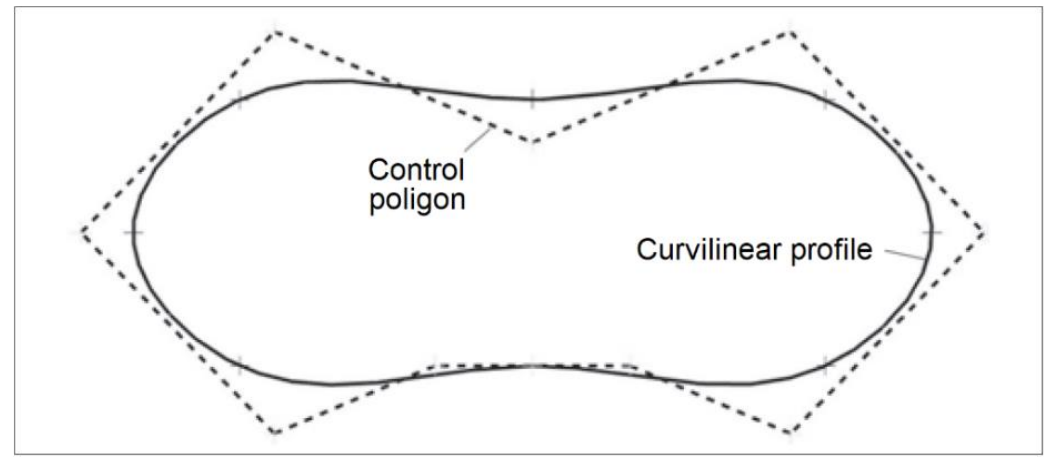

Fig. 1. Nominal contour of the hole and curvilinear stub

The MasterCAM system built a CAD model of objects and prepared programs controlling the machining. Finishing was carried out with a high speed steel end mill with a diameter of $\varnothing 10 \mathrm{~mm}$ (three blades). The following finishing parameters were adopted:

- feedrate $-300 \mathrm{~mm} / \mathrm{min}(0.02 \mathrm{~mm} /$ tooth $)$,

- cutting speed $-157 \mathrm{~m} / \mathrm{min}$,

- spindle revolutions - $5000 \mathrm{rpm}$,

- allowance $0.3 \mathrm{~mm}$,

- offset between the hole and stub at $0.05 \mathrm{~mm}$.

The elements (fig. 2) are made of aluminum alloy PA6 (2017A).

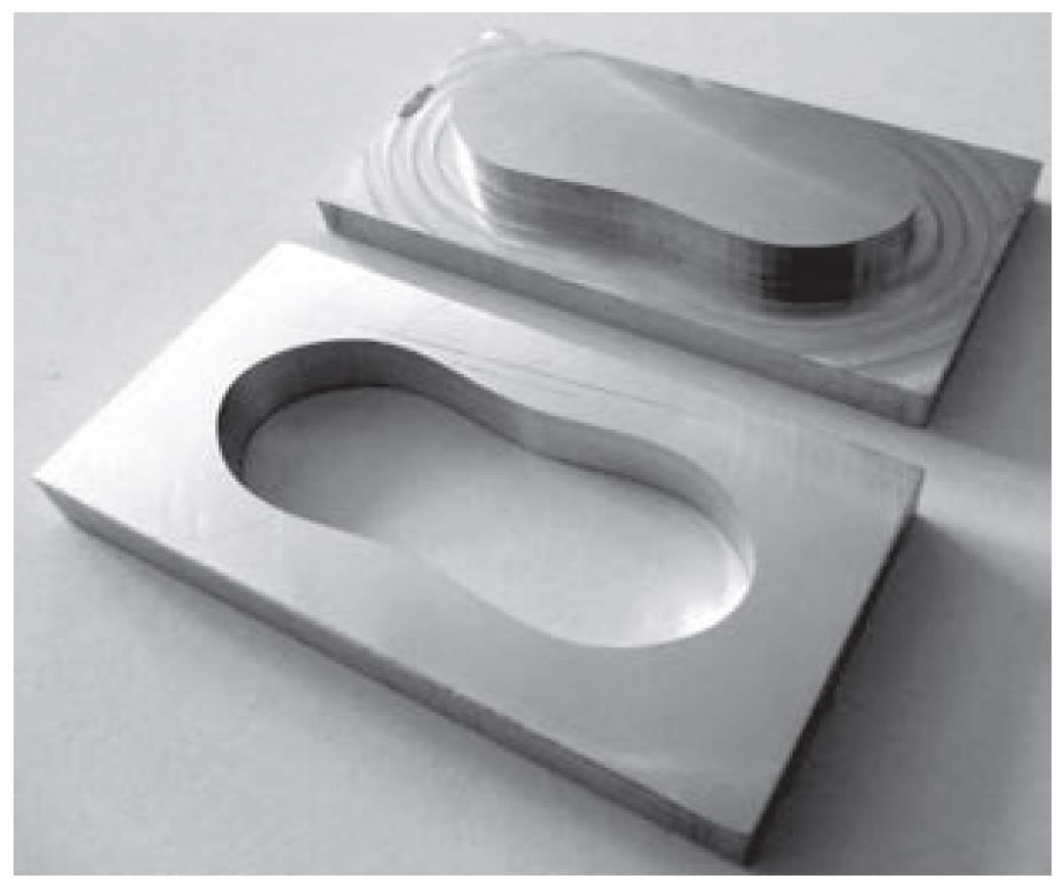

Fig. 2. Hole and curvilinear stub produced

After finishing the manufacturing stage, the machined objects were subjected to control measurements. They were carried out on a Global Performance measuring machine by Hexagon Metrology (PC-DMIS software, MPEE $=1.5+L / 333[\mathrm{~mm}]$, Renishaw SP25M measuring head, $20 \mathrm{~mm}$ long stylus with spherical tip diameter $\varnothing 2 \mathrm{~mm}$ ). The automatic scanning procedure used in the PC-DMIS system was used. The "closed linear scan" procedure (fig. 3) requires an indication of the scan start point and a second point determining the scan direction. A maximum distance between measuring points (in this case $1 \mathrm{~mm}$ ) is also defined. The nominal surface model of manufactured elements was used in the preparation of this procedure. 
Based on the information provided, the system automatically generates nominal coordinates of the measuring points and vectors of the measuring tip pointing perpendicular to the measured profile. An identical distribution of 143 measurement points was obtained in the spigot and hole measurement (fig. 4).

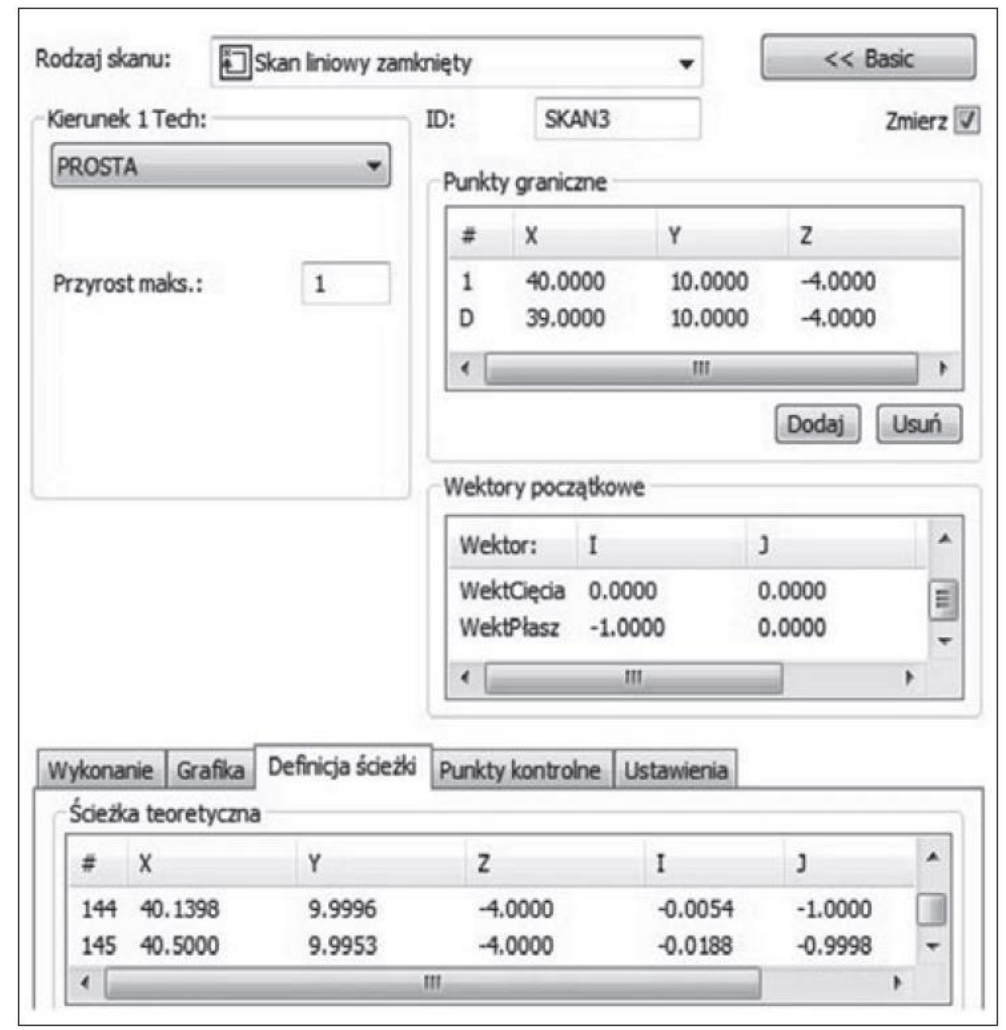

Fig. 3. Closed linear scan window

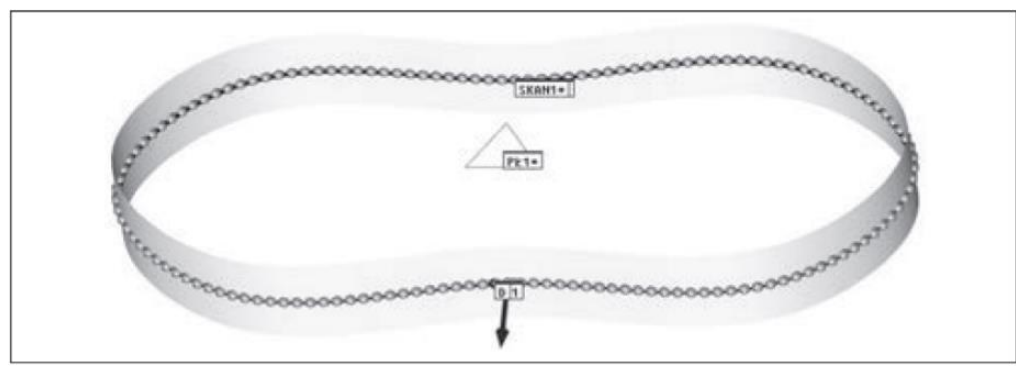

Fig. 4. Distribution of measuring points

As a result of coordinate measurements, two sets of observed deviations were obtained. These deviations were determined in the same nominal coordinates of the outline describing the stub and the hole. Results of coordinate measurements are summarized in tab. I. The expected machining accuracy was not achieved for both the hole and the stub.

At the measuring points, differences of deviations observed for the hole and stub were additionally determined (tab. II). They contain information about the local distance between the contours (gap).

Fig. 5 shows distributions of the observed deviations of the stub and hole (deviations are presented on a scale of 20:1 in relation to the nominal contour). They also illustrate distribution of the gap between two elements.

TABLE I. Coordinate measurement results

\begin{tabular}{|l|c|r|}
\hline & \multicolumn{1}{|c|}{ Stub } & \multicolumn{1}{c|}{ Hole } \\
\hline Maximum deviation [mm] & -0.080 & 0.103 \\
\hline Minimal deviation [mm] & -0.018 & -0.014 \\
\hline Standard deviation [mm] & 0.0135 & 0.0297 \\
\hline Mean value [mm] & -0.058 & 0.062 \\
\hline
\end{tabular}

TABLE II. Designated distances between contours

\begin{tabular}{|l|l|}
\hline Maximum distance $[\mathrm{mm}]$ & 0.167 \\
\hline Minimum distance $[\mathrm{mm}]$ & 0.046 \\
\hline Standard deviation $[\mathrm{mm}]$ & 0.026 \\
\hline Mean value $[\mathrm{mm}]$ & 0.120 \\
\hline
\end{tabular}


The largest value of the contour shift observed is $0.167 \mathrm{~mm}$, the smallest is $0.046 \mathrm{~mm}$. The maximum value exceeds the contour offset value assumed at the beginning three times. The wide range of gap variation between elements raises reservations.

Due to the fact that the effects of curvilinear profile machining did not meet the requirements, the procedure of increasing the manufacturing accuracy was carried out. It was aimed at increasing the accuracy of machining the profiles themselves and obtaining an appropriate gap between contours produced.

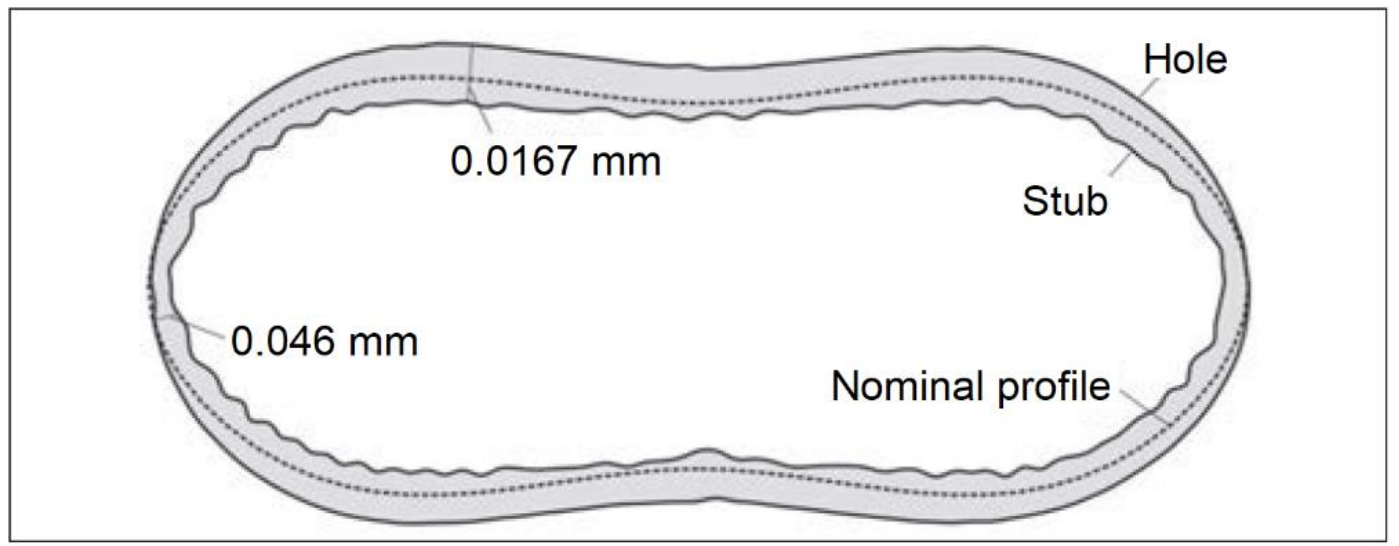

Fig. 5. Distribution of machining deviations of the stub and the hole

\section{Improving the accuracy of the hole and curvilinear stub production}

The method used to increase the accuracy of curvilinear profile production [7] is implemented in the following stages:

- coordinate measurements of the created object, determination of observed deviations and their components,

- determination of corrected profile coordinates at measuring points,

- reconstruction of the nominal geometric model of the manufactured profile, creation of corrected machining programs and workpiece machining,

- coordinate measurements and assessment of improving the accuracy of curvilinear profile production.

Basic element of the proposed method is the process of rebuilding the geometric model of the manufactured object. It starts with the implementation of coordinate control measurements of the pre-machined profile. The measurement results contain information on observed machining deviations. The measure of the deviations is the distance between the points on the profile (nominal CAD model) and the corresponding points observed as a result of the measurements. After conducting the coordinate measurements, the construction of two corrected geometric models of the profile (stub and hole) was started. At the initial stage of the correction process, the nominal coordinates and observed coordinates of 143 measuring points were separated from the measurement program. On their basis, two sets of corrected coordinates were determined. Then, two corrected curves describing the profile produced were created in the MASTERCAM system. These curves compensated for machining deviations and were used to re-generate machining programs. It was assumed that the maximum contour offset of the stub relative to the hole should not be greater than $0.05 \mathrm{~mm}$.

After re-treatment of the elements, coordinate measurements were again carried out. The analysis of their results showed significant improvement in the accuracy of curvilinear profile production. Basic information about the results of measurements is provided in tab. III. They show that the maximum deviation in the machining of the hole was reduced more than five times. In the case of the stub, this deviation more than doubled.

TABLE III. Results of repeated coordinate measurements

\begin{tabular}{|l|r|r|}
\hline & \multicolumn{1}{|c|}{ Stub } & \multicolumn{1}{c|}{ Hole } \\
\hline Maximum deviation [mm] & -0.035 & 0.018 \\
\hline Minimal deviation $[\mathrm{mm}]$ & -0.007 & -0.0007 \\
\hline Standard deviation $[\mathrm{mm}]$ & 0.0064 & 0.0032 \\
\hline Mean value [mm] & -0.0177 & 0.007 \\
\hline
\end{tabular}

\section{TABLE IV. Determined distances between contours after profile correction}

\begin{tabular}{|l|l|}
\hline Maximum distance $[\mathrm{mm}]$ & 0.044 \\
\hline Minimum distance $[\mathrm{mm}]$ & 0.010 \\
\hline Standard deviation $[\mathrm{mm}]$ & 0.006 \\
\hline Mean value $[\mathrm{mm}]$ & 0.024 \\
\hline
\end{tabular}


Tab. IV summarizes basic data regarding the determined differences in the observed deviations of stub and hole at the measuring points. They inform about the local width of the gap between two elements. Results indicate that the maximum size of the contour offset decreased from $0.167 \mathrm{~mm}$ to $0.044 \mathrm{~mm}$. The average gap between the hole and the stub was reduced from $0.120 \mathrm{~mm}$ to $0.024 \mathrm{~mm}$. These results indicate that a much greater degree of fitting of two curvilinear contours was achieved.

Graphical distribution of the observed deviations after corrective machining and related distribution of the gap between the elements is shown in fig. 6 . A thin line marks the results obtained before the correction.

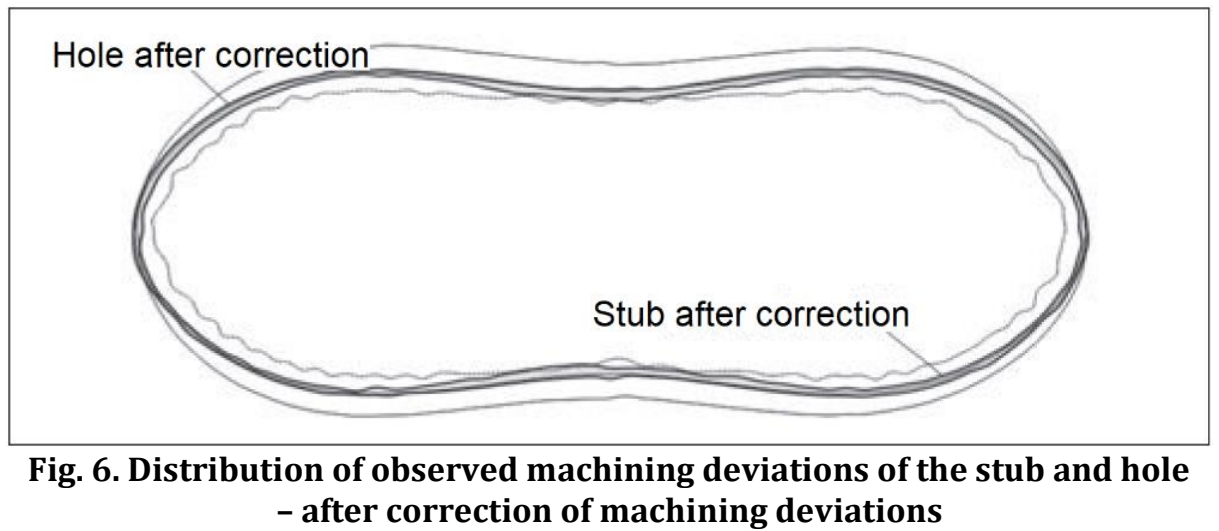

\section{Summary}

The procedure presented in the paper makes it possible to assess the degree of fitting of a stub and a hole with a curvilinear contour. In this case, coordinate measurements are necessary.

Information about the observed deviations of two profiles provide knowledge about the local size of the gap and its distribution along the entire length of the profile. The range of gap variation and its distribution allow for the assessment of achieved degree of cooperating profiles fitting. This has a large impact on the proper functioning of such elements as blanking dies or closing elements of injection mold dies. If the correct contour accuracy is not achieved, one can use the method to increase the accuracy of machining the contours of the hole and stub. As shown, the method presented in the paper significantly increased the accuracy of both profiles. It also made it possible to achieve smaller size gap and more even distribution.

\section{REFERENCES}

[1] Cho M.W., Seo T.I., Kwon H.D. "Integrated error compensation method using OMM system for profile milling operations". Journal of Materials Processing Technology. 136 (2003): 88-99, https://doi.org/10.1016/S09240136(02)00943-3.

[2] Chua C.H., Huanga W.N., Hsu Y.Y. "Machining accuracy improvement in five-axis flank milling of ruled surfaces". International Journal of Machine Tools \& Manufacture. 48 (2008): 914-921, https://doi.org/10.1016/j.ijmachtools.2007.10.023.

[3] Poniatowska M., Werner A. "Fitting spatial models of geometric deviations of free-form surfaces determined in coordinate measurements". Metrology and Measurement Systems. 17, 4 (2010): 599-610, https://doi.org/10.2478/v10178-010-0049-x.

[4] Bera T.C., Desai K.A., Rao P.V.M. "Error compensation in flexible end milling of tubular geometries". Journal of Materials Processing Technology. 211 (2011): 24-34, https://doi.org/10.1016/i.jmatprotec.2010.08.013.

[5] Chen Y. et all. "Spatial statistical analysis and compensation of machining errors for complex surfaces". Precision Engineering. 37 (2013): 203-212, https://doi.org/10.1016/i.precisioneng.2012.08.003.

[6] Cho M.W. et all. "Integrated machining error compensation method using OMM data and modified PNN algorithm". International Journal of Machine Tools \& Manufacture. 46 (2006): 1417-1427, https://doi.org/10.1016/j.ijmachtools.2005.10.002.

[7] Werner A. "Korekcja odchyłek obróbkowych profili 2D opisanych krzywymi NURBS". Mechanik. 8-9 (2018): 716718, https://doi.org/10.17814/mechanik.2018.8-9.113. 